\title{
Infant with Life Threatening Thymic Carcinoma
}

\author{
Basil Khadim Abdullah ${ }^{1 *}$, Zardasht Bakr Mohammed ${ }^{1}$, Khalid Hama Salih², Aram Baram³, Dashti \\ Latif Muhealddina ${ }^{1}$, Ali Omer Qadir ${ }^{1}$, Rebwar Ahmed Shrif ${ }^{1}$, Rzgar Ghareeb Muhamed ${ }^{3}$ \\ ${ }^{1}$ Pediatric Department-Hiwa Teaching Hospital -Sulemania, Iraq \\ ${ }^{2}$ Pediatrics Department, College of Medicine, University of Sulaimania \\ ${ }^{3}$ Department of Cardiovascular and Thoracic Surgery, School of Medicine, University of Sulaimania \\ * Corresponding author email: basilonc@yahoo.com
}

Received: 05 June 2019 / Revised: 24 July 2019 / Accepted: 25 July 2019 / Published: 26 July 2019

\begin{abstract}
Thymic epithelial neoplasms consist of thymomas, thymic carcinoids and thymic carcinomas. Carcinomas are malignant tumors of the thymus; they compromise only $4 \%-14 \%$ of thymic epithelial neoplasms. Thymic carcinoma cells do not resemble healthy cells but similar to cancer cells that originate from other parts of the body and grow more quickly when the tumor is found and more difficult to treat. Thymic carcinoma rarely occurs in children. We reported a case of undifferentiated thymic carcinoma in 11 months old female. After two courses of chemotherapy the patient developed increasing respiratory compression and unfortunately died because of respiratory failure.
\end{abstract}

Keywords: Anterior Mediastinal Mass, Rare Pediatric Tumors, Thymic Carcinoma.

\section{Case Report}

11 months old infant presented to our consultation department as a referred case from pediatric teaching hospital as a case of anterior mediastinal mass, the mother gave a history of flu like illness since 1 months that lasted 3 days without any treatment after that the baby developed elevation in body temperature that's why they consulted a consultant pediatrician who admitted her to the pediatric ward and treated as a case of bronchiolitis, she was admitted in hospital for 1 week and then discharged with some improvement on oral treatment but unfortunately the baby after two days again developed high grade fever in deterioration of the cough in severity and frequency and associated with shortness of breath that's why the doctor sent a CXR and complete investigations which revealed a big anterior mediastinal mass which was suspicious to the pediatrician, who send her to chest CT scan which confirmed what is seen in the CXR report, after that the patient was referred for a cardiothoracic surgeon for further management who took a biopsy of the mass and sent her to our hospital, we admitted the patient and started work up by sending full investigations including all blood tests and also review of the slide for histopathology and Immunohistochemistry confirmation.

Regarding the antenatal history the mother was on very good antenatal care and the natal history the baby was delivered with cesarean section because of absent dilatations and in efficient contraction without any complication even not needed to enter the NCU. There is no known allergy to any drug, there is no history of operation and there is no family history of such a condition, the baby lives in a good socioeconomic status

\section{Physical Examination}

The child was ill locking, dysneic, tachypnic and pale. Vital signs are follows:

PR: 100 b pm, RR: 40 /min, BP 110/70 mmhg, TEMP: $37.1 \mathrm{C}, \mathrm{SPO}_{2}: 60$ without $\mathrm{O}_{2}$ and 87 with $\mathrm{O}_{2}$, RBS: $128 \mathrm{mg} / \mathrm{dl}$.

No Lymphadenopathy, no organomegaly, no clubbing of finger, no jaundiced and auscultation of 
Infant with Life Threatening Thymic Carcinoma

the chest was decreased air entry in the right lung with fine crepitation

We started supportive life saving measures by giving oxygen via nasal canula and steroids and sent for the following laboratory investigation-

(complete blood count. blood film, electrolytes, tumor markers, ESR, CRP, LDH, ALP, coagulation factors viral screening, ferritin, acetyl choline esterase inhibitor antibody, and 24 hours urine for Vanillylmandelic Acid) also sent for imaging study which are CXR, echocardiography and abdominal ultrasound

Results of laboratory investigation shows in Table 1.

Table 1: Laboratory investigation results

\begin{tabular}{|c|c|}
\hline Investigation & Result \\
\hline Hb:(hemoglobin) & $10.6 \mathrm{~g} / \mathrm{dl}$ \\
\hline WBC & 6,300 cells per microliter \\
\hline Platelets Count & 375,000 platelets/mcL \\
\hline ESR & $47 \mathrm{~mm} / \mathrm{h}$ \\
\hline CK & $0.59 \mathrm{ukat} / \mathrm{L}$ \\
\hline CRP & $13.2 \mathrm{mg} / \mathrm{L}$ \\
\hline LDH & $391 \mathrm{IU}-\mathrm{L}$ \\
\hline Serum ferritin & $72 \mathrm{ng} / \mathrm{mL}$ \\
\hline B-hcg & $<0.100 \mathrm{mlU} / \mathrm{ml}$ \\
\hline S.AFP & $25.23 \mathrm{IU} / \mathrm{ml}$ \\
\hline $\begin{array}{c}\text { Serum Anti- } \\
\text { Acetylcholine } \\
\text { receptor }\end{array}$ & $0.2 \mathrm{nmol} / \mathrm{L}$ \\
\hline 24 Hour Urine VMA & $1.00 \mathrm{mg} / 24 \mathrm{~h}$ \\
\hline
\end{tabular}

Regarding image study include CXR with a huge anterior mediastinal mass occupying most of right lung and part of left lung (Figure 1), abdominal US was normal, echocardiography was normal with Ejection fraction $74 \%$ and fractional shortening $42 \%$. CT scan of chest with IV Iodine contrast reveal $8 * 5 \mathrm{~cm}$ mass lesion seen occupying most of the mediastinum and extending superiorly to the right side of neck, its displacing vessels including right pulmonary artery and SVC, it has large mass effect with partial collapse of the right lower lung and mild right side pleural effusion, the mass doesn't show internal calcification or fatty tissue (Figure2)

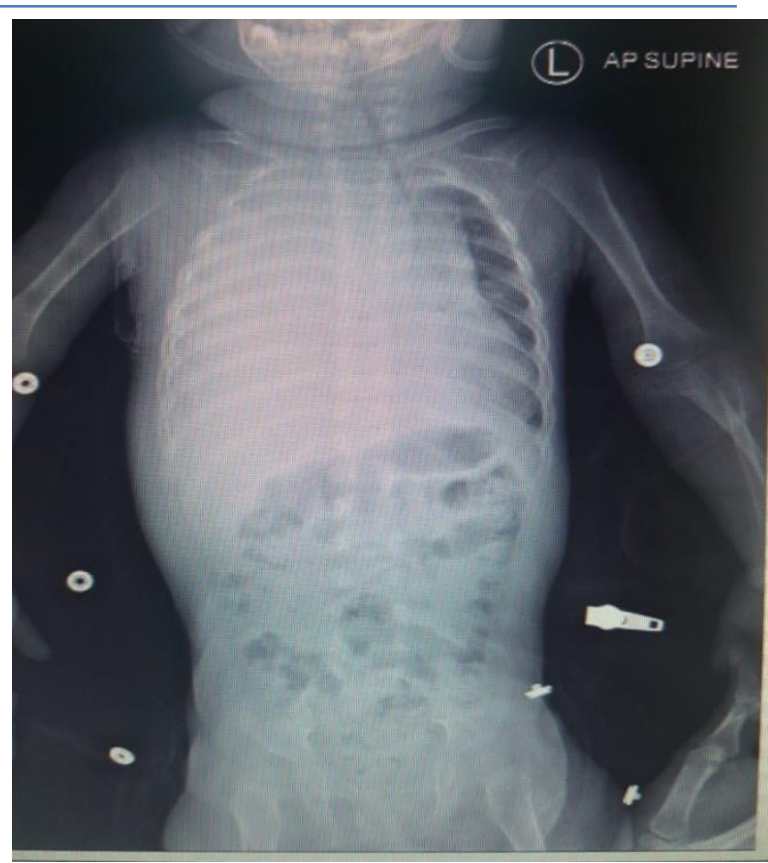

Figure 1: Anterior Posterior Chest X-ray Shows total collapse of right lung and part of left lung.

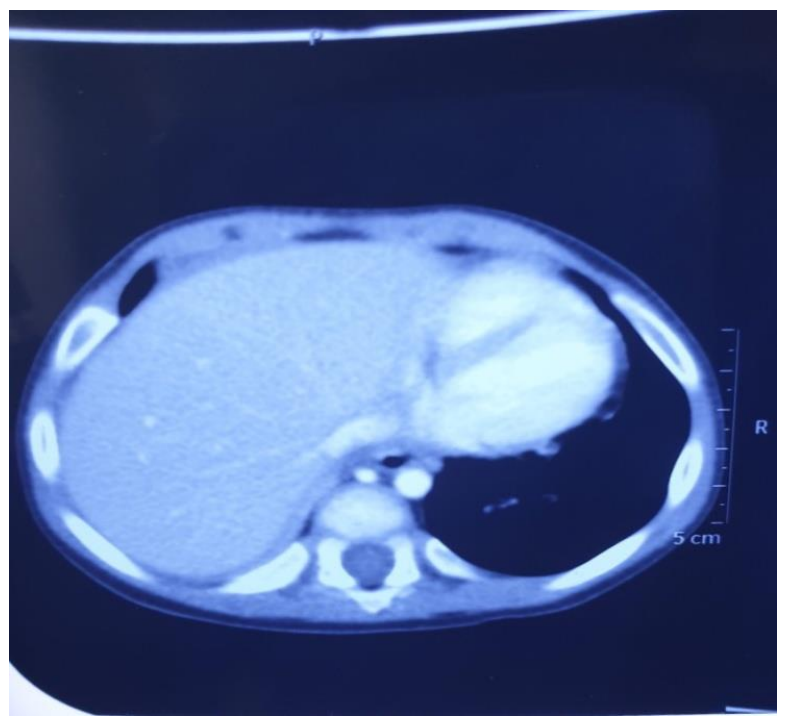

Figure 2: Chest CT scan Shows large mass with partial right lung collapse.

A biopsy by cardiothoracic surgeon from anterior mediastinal mass was performed as it was considered inoperable. Immunohistochemistry was done with positive controls shows the following reactions:

AE1/AE3: positive, moderate staining for large cells EMA: positive

CD79a: positive

Negative for (Chromogranin, CD5, CD3, CD20, CD30, CD117, WT1, TDT, Myogenin, CD34, CD45, LCA, PLAP and Vimentin); negative reaction to these markers exclude neural tumors, 
Abdullah et al., Int. Ann. Sci.; Vol. 7, Issue 1, pp: 53-57, 2019

lymphomas, leukemia, and large subset of germ cell tumor.

As the patient diagnosed, we put him on steroid drug and next day we started neoadjuvant chemotherapy as first cycle included (cisplatin for 1 day, etoposide for 3 days and doxorubicin for 2 days) but because the patient is not so stable, we modify chemotherapy to only $50 \%$.

At the beginning the radiation oncologist couldn't give irradiation to the patient because of nearby to heart and other vital organs. Later on, she developed SVC syndrome which is caused by pressure effect of the tumor on the superior vena cava vein and they started irradiation to that site (1900 cGy).

A second cycle of chemotherapy has been given after 21 days from first cycle which containing (etoposide, ifosfamide and cisplatin) but still no respond and couldn't do surgical resection. After two courses of chemotherapy the patient developed increasing respiratory compression and unfortunately died because of respiratory failure.

\section{Discussion}

Thymic carcinoma rarely occurs in children. Only two pediatric cases were described in 19 clinopathological studies including 305 cases analyzed by Chung [1]. we could find only 14 cases [2] in English literature. Thymic tumors account for $1.5 \%$ of mediastinal mass in children [3]. Thymic epithelial neoplasms represent a diverse group of tumors ranging from well differentiated thymomas to obviously malignant tumors [3], [4]. Thymic carcinoma has several subtypes which include squamous cell carcinoma, lymphoepithelioma like carcinoma, clear cell sarcoma, and undifferentiated thymic carcinoma [1], [4]-[7]. Myasthenia gravis and other paraneoplastic syndromes are rarely associated with thymic carcinoma unlike to thymoma [6], [8].

Thymic carcinoma arisen from epithelium and microscopically could be type B3 with round or polygonal shape or type $\mathrm{C}$ with many histological subtyping which includes squamous cell, lymphoepithelioma-like, sarcomatoid, clear cell, basaloid, mucoepidermoid, papillary and undifferentiated carcinoma. The World Health
Organization in 2015 developed a classification of tumors of the thymus (Table2) [9].

Table 2: WHO classification.

\begin{tabular}{|l|l|}
\hline Type & \multicolumn{1}{|c|}{ Histological description } \\
\hline A & Medullary thymoma. \\
\hline AB & Mixed thymoma. \\
\hline B1 & Predominantly cortical thymoma. \\
\hline B2 & Cortical thymoma. \\
\hline B3 & Well-differentiated thymic carcinoma. \\
\hline C & Thymic carcinoma. \\
\hline
\end{tabular}

Our patient has a histological subtype of undifferentiated carcinoma. Undifferentiated carcinoma some time also called anaplastic subtype associated with a highly aggressive behavior with poor prognosis [10]-[12]. The diagnosis of this subtype is one of exclusion, our patient was complaining of sever progressive dyspnea and low SPO2. CXR showed huge anterior mediastinal mass, CT scan showed $8 * 5$ $\mathrm{cm}$ mass lesion seen occupying most of the mediastinum and extending superiorly to the right side of neck, this manifestation is called superior vena cava syndrome which is caused by pressure effect of the tumor on the superior vena cava vein.

\subsection{We are Still using Masaoka Staging System for Thymic Carcinoma}

Stage 1: Completely encapsulated and microscopically no capsular invasion.

Stage 2: 1. Macroscopic invasion into surrounding fatty tissue or mediastinal pleura

2. Microscopic invasion into capsule

Stage 3: Macroscopic invasion into neighboring organ, i.e., pericardium, great vessels, or lung

Stage $4 a$ : pleural or pericardial dissemination

Stage $4 b$ : lymphogenous or hematogenous metastasis

Surgery is the primary treatment for thymic carcinoma with complete surgical resection as a 
local control but because in most of patients surgery cannot be done at diagnosis due to local invasion of viable structures and metastasis, radiation used as a second line for local control and cisplatin based regimens have also proved to be effective in the treatment [1], [10], [13], [14]. Our patient was inoperable because of attachment to vital organ so we gave her radiation therapy (3500 cGy) and chemotherapy regimen containing cisplatin. After two courses of chemotherapy the patient developed increasing respiratory compression and unfortunately died because of respiratory failure. The prognosis of thymic carcinoma is poor [1], [10], [13], [14]. In summary thymic carcinoma although rare in infant age but we reported an 11 months old female with this aggressive tumor.

\section{Conclusion}

Thymic carcinoma is rare tumor of thymus and complete resection of tumor is the best way to achieve long term survival if feasible as a local control, our patient was inoperable, so we were started with radiotherapy and chemotherapy hopefully for getting better but the patient unfortunately died because a poor prognosis nature of thymic carcinoma in pediatric. Most thymic tumors in pediatric patients are inoperable at diagnosis, which results in poor prognosis. Improved chemotherapy approaches are needed.

\section{Abbreviations}

SVC: Superior Vena Cava; CT: Computed Tomography; CXR: Chest X-Ray; PR: Pulse Rate; RR: Respiratory Rate; BP: Blood Pressure; TEMP: Temperature; $\mathbf{O}_{2}$ : Oxygen; RBS: Random Blood Sugar; ESR: Erythrocyte Sedimentation Rate; CK: Creatinine Kinase; CRP: C - reactive protein; LDH: Lactate Dehydrogenase; ALP: Alkaline Phosphatase; LFT: Liver Function Test; RFT: Renal Function Test; WBC: White Blood Test; gran: granulocyte; PLT: Platelet; NCU: Neonatal Care Unit; VMA: Vanillylmandelic Acid; AFP: Alpha Feto Protein; B-hCG: Beta Human Chorionic Gonadotropin; US: Ultrasonography; IV: Intravenous.

\section{Declarations}

\subsection{Acknowledgements}

We gratefully acknowledge the patient's parents for allowing us to publish their case report.

\subsection{Ethical Approval}

Ethical approval for this case report was obtained from the ethical committee of Hiwa Teaching Hospital.

\subsection{Informed Consent}

Written informed consent was obtained from patient's parent for this case report.

\subsection{Funding Source}

Not applicable.

\subsection{Competing Interests}

The authors declared that they have no conflict of interests.

\section{How to Cite this Article:}

B. Abdullah et al., "Infant with Life Threatening Thymic Carcinoma", Int. Ann. Sci., vol. 7, no. 1, pp. 53-57, Jul. 2019. doi:10.21467/ias.7.1.53-57

\section{References}

[1] D. A. Chung, "Thymic Carcinoma - Analysis of Nineteen Clinicopathological Studies," Thorac. Cardiovasc. Surg., vol. 48, no. 2, pp. 114-119, Apr. 2000.

[2] S. R. y Cajal and S. Suster, "Primary Thymic Epithelial Neoplasms in Children," Am. J. Surg. Pathol., vol. 15, no. 5, pp. 466-474, 1991.

[3] J. L. Grosfeld, M. A. Skinner, F. J. Rescorla, K. W. West, and L. R. Scherer, "Mediastinal tumors in children: Experience with 196 cases," Ann. Surg. Oncol., vol. 1, no. 2, pp. 121-127, Mar. 1994.

[4] J. Rosai and L. H. Sobin, Histological Typing of Tumours of the Thymus. Berlin, Heidelberg: Springer Berlin Heidelberg, 1999.

[5] M. Marino and H. K. Müller-Hermelink, "Thymoma and thymic carcinoma. Relation of thymoma epithelial cells to the cortical and medullary differentiation of thymus.," Virchows Arch. A. Pathol. Anat. Histopathol., vol. 407, no. 2, pp. 119-49, 1985.

[6] C.-A. Hartmann, C. Roth, C. Minck, and G. Niedobitek, "Thymic carcinoma," J. Cancer Res. Clin. Oncol., vol. 116, no. 1, pp. 69-82, Jan. 1990.

[7] M. R. Wick, B. W. Scheithauer, L. H. Weiland, and P. E. Bernatz, "Primary thymic carcinomas.," Am. J. Surg. Pathol., vol. 6, no. 7, pp. 613-30, Oct. 1982.

[8] K. Swinborne-Sheldrake, G. F. Gray, and A. D. Glick, “Thymic epithelial neoplasms.," South. Med. J., vol. 78, no. 7, pp. 790-800, Jul. 1985. 
Abdullah et al., Int. Ann. Sci.; Vol. 7, Issue 1, pp: 53-57, 2019

[9] A. Masaoka, Y. Monden, K. Nakahara, and T. Tanioka, "Follow-up study of thymomas with special reference to their clinical stages," Cancer, vol. 48, no. 11, pp. 2485-2492, Dec. 1981.

[10] S. Suster and J. Rosai, "Thymic carcinoma. A clinicopathologic study of 60 cases.," Cancer, vol. 67, no. 4, pp. 1025-32, Feb. 1991.

[11] L. Chalabreysse, B. Etienne-Mastroianni, P. Adeleine, J.-F. Cordier, T. Greenland, and F. Thivolet-Bejui, "Thymic carcinoma: a clinicopathological and immunohistological study of 19 cases," Histopathology, vol. 44, no. 4, pp. 367-374, Apr. 2004.

[12] C. P. Hsu et al., "Thymic carcinoma. Ten years' experience in twenty patients.," J. Thorac. Cardiovasc. Surg., vol. 107, no. 2, pp. 615-20, Feb. 1994.

[13] K. Kondo and Y. Monden, "Therapy for thymic epithelial tumors: a clinical study of 1,320 patients from Japan," Ann. Thorac. Surg., vol. 76, no. 3, pp. 878-884, Sep. 2003.

[14] A. Ríos et al., "Prognostic factors in thymic epithelial neoplasms," Eur. J. Cardio-Thoracic Surg., vol. 21, no. 2, pp. 307-313, Feb. 2002
Publish your research article in AIJR journals-

$\checkmark$ Online Submission and Tracking

$\checkmark$ Peer-Reviewed

$\checkmark$ Rapid decision

$\checkmark \quad$ Immediate Publication after acceptance

$\checkmark \quad$ Articles freely available online

$\checkmark \quad$ Retain full copyright of your article.

Submit your article at journals.aijr.in

\section{Publish your books with AIJR publisher-}

$\checkmark \quad$ Publish with ISBN and DOI.

$\checkmark$ Publish Thesis/Dissertation as Monograph.

$\checkmark$ Publish Book Monograph.

$\checkmark$ Publish Edited Volume/ Book.

$\checkmark$ Publish Conference Proceedings

$\checkmark \quad$ Retain full copyright of your books.

Submit your manuscript at books.aijr.org 